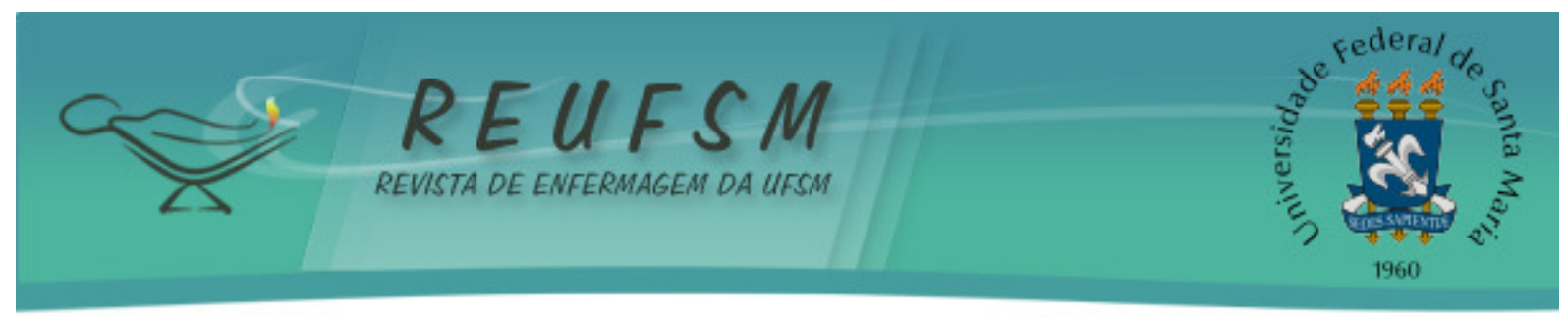

ARTIGO ORIGINAL

\title{
SABER POPULAR: USO DE PLANTAS MEDICINAIS COMO FORMA TERAPÊUTICA NO CUIDADO À SAÚDE*
}

\section{POPULAR KNOWLEDGE: THE USE OF MEDICINAL PLANTS AS THERAPEUTIC FORM IN HEALTH CARE}

\section{SABER POPULAR: EL USO DE PLANTAS MEDICINALES COMO TERAPÉUTICO EN EL CUIDADO DE LA SALUD}

Doi: $10.5902 / 2179769217945$

\author{
Marcio Rossato Badke ${ }^{1}$ \\ Caterine Angélica Somavilla² \\ Elisa Vanessa Heisler ${ }^{3}$ \\ Andressa de Andrade ${ }^{4}$ \\ Maria de Lourdes Denardin Budó 5 \\ Tânea Maria Bisognin Garlet ${ }^{6}$
}

RESUMO: Objetivo: conhecer os saberes e práticas de moradores da região urbana do noroeste do estado do Rio Grande do Sul, acerca do uso de plantas medicinais como forma terapêutica no cuidado à saúde. Método: pesquisa qualitativa do tipo exploratório descritivo, com coleta de dados baseada em entrevista semiestruturada e observação participante. Total de dez entrevistados, usuários de plantas medicinais, selecionados por meio da rede de relações sociais. A coleta ocorreu no período de julho a setembro de 2011. Resultados: na análise temática, emergiram os temas: tipos de plantas e suas indicações; e quem indicou o uso da planta. Considerações finais: as maiorias das indicações populares foram ao encontro da ciência, e os conhecimentos são passados de geração para geração. Sendo assim, sugere-se que o enfermeiro insira-se na comunidade para conhecer ou reconhecer as práticas populares, aproximando-as do saber científico, proporcionando um cuidado integral ao usuário, respeitando seus hábitos e costumes.

Descritores: Plantas; Terapias complementares; Cultura; Assistência integral à saúde; Enfermagem.

ABSTRACT: Aim: to know the knowledge and practices of inhabitants of the urban region of northwestern Rio Grande do Sul, which makes use of medicinal plants as a therapeutic way in health care. Method: qualitative research, an exploratory and descriptive study, with data collection based on semi-structured interviews and participant observation. Total of ten respondents, users of medicinal plants, selected through the network of social relations. The collection took place from July to September 2011. Results: From the thematic analysis, emerged the themes: types of plants and their indications; who

\footnotetext{
* Pesquisa financiada pelo Conselho Nacional de Desenvolvimento Científico e Tecnológico - CNPQ

${ }^{1}$ Enfermeiro, Mestre em Enfermagem, Doutorando da FEn/UFPel, Professor Adjunto da Universidade Federal de Santa Maria - UFSM, RS, Brasil. E-mail: marciobadke@gmail.com

${ }^{2}$ Enfermeira, Responsável pela CCIH da instituição Associação Hospital Nossa Senhora da Piedade, Nova Palma, RS, Brasil. email: cate_df@hotmail.com

${ }^{3}$ Enfermeira, Mestre em Enfermagem pela Universidade Federal de Santa Maria, Enfermeira da Prefeitura Municipal de Tiradentes do Sul, RS, Brasil.email: elisa.vanessa@yahoo.com.br

${ }^{4}$ Enfermeira, Mestre em ciências da saúde, Doutoranda em Ciências da Saúde na Universidade Federal do Rio Grande(FURG), Professora Assistente III na Universidade Federal de Santa Maria (UFSM), Campus de Palmeira das Missões, RS, Brasil. email: andressa@ufsm.br

${ }^{5}$ Enfermeira, Doutora. UFSM, Santa Maria, RS, Brasil. lourdesdenardin@gmail.com.

6 Professora Adjunta, Dra. em Agronomia, Departamento de Zootecnia e Ciências Biológicas Universidade Federal de Santa Maria - UFSM - campus Palmeira das Missões, RS, BR. email:taneagarlet@hotmail.com
} 


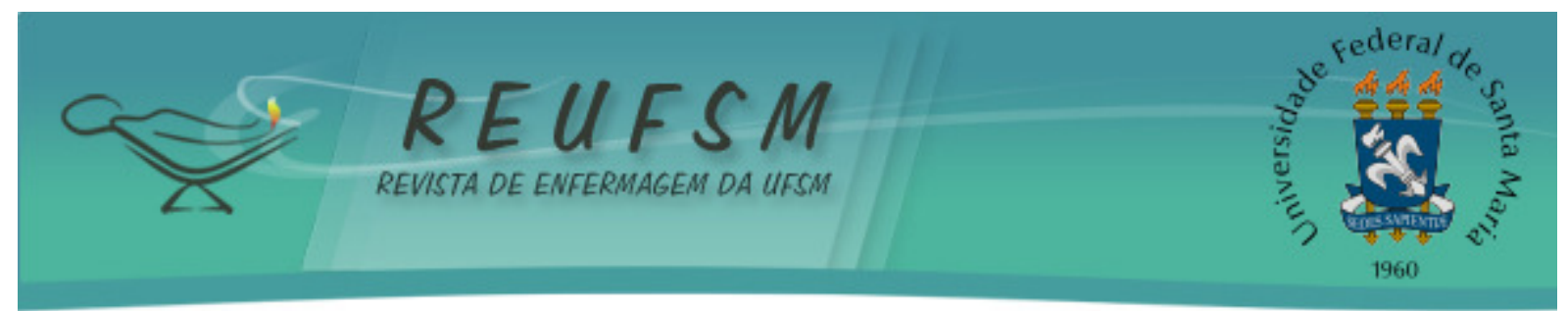

indicated the use of the plant. Final Thoughts: most popular indications is compatible with science and knowledge is passed from generation to generation. Therefore, it is considered to be essential that the nurse inserts himself in the community to know or recognize the popular practices, approaching the scientific knowledge, providing complete care to users, respecting their habits and customs.

Descriptors: Plants; Complementary therapies; Culture; Comprehensive health care; Nursing.

RESUMEN: Objetivo: conocer las prácticas de residentes de la región urbana del noroccidental del estado del Rio Grande del Sur, sobre el uso de plantas medicinales como terapéutico en la atención a la salud. Método: investigación cualitativa exploratoria y descriptiva, con recolección de datos basada en entrevista semiestructurada y observación participante. Total de diez entrevistados, usuarios de plantas medicinales, seleccionados a través de la red de relaciones sociales. La colección ocurrió entre julio y septiembre de 2011. Resultados: en el análisis temático surgieron los temas: tipos de plantas y sus pormenores; y quién indicó el uso de la planta. Consideraciones finales: las indicaciones populares fueron al encuentro de la ciencia, y los conocimientos se transmiten de generación en generación. Es esencial la inserción de la enfermera en la comunidad para conocer/reconocer las prácticas populares, acercándola al conocimiento científico y proporcionando atención integral a los usuarios, respetando sus usos y costumbres.

Descriptores: Plantas; Terapias complementarias; Cultura; Atención integral de salud; Enfermería.

\section{INTRODUÇÃO}

A utilização das plantas medicinais como forma terapêutica vem acompanhando o homem através dos tempos, fazendo parte de sua cultura. Durante várias gerações a população de cada região do país, tinha como única forma de tratamento para seus males, o uso empírico de plantas medicinais de fácil acesso, muitas vezes, identificando as indicações das mesmas por meio da sua utilização. Dessa forma, o uso das plantas se tornou uma prática de cuidado tradicional de saúde e já é revelada em diversos estudos como de uso para fins terapêuticos por uma parcela significativa da população. ${ }^{1-2}$

No Brasil, o uso de plantas medicinais no tratamento de enfermidades tem influências da cultura indígena, africana e europeia, cujas marcas foram integradas em um conjunto de princípios que visam à cura de doenças e restituem ao homem a vida natural. ${ }^{3}$

Mesmo com o incentivo da indústria farmacêutica para a utilização de medicamentos industrializados, grande parte da população ainda faz uso de práticas terapêuticas no cuidado à saúde, como as plantas medicinais, utilizadas para aliviar ou mesmo curar algumas enfermidades. ${ }^{4}$ Isso pode ocorrer devido ao alto custo dos medicamentos industrializados ou, então, pelo fato de os usuários estarem buscando alternativas que possuam menos efeitos colaterais para o tratamento de doenças. ${ }^{5}$

No Brasil, no dia 22 de junho de 2006, foi aprovada por base no Decreto 5.813, a Política Nacional de Plantas Medicinais e Fitoterápicos que visa garantir à população o acesso seguro e o uso racional de plantas medicinais e fitoterápicos, promovendo o uso sustentável da biodiversidade, o desenvolvimento da cadeia produtiva e da indústria nacional. ${ }^{6}$

Ao tratar mais especificadamente do Estado do Rio Grande do Sul, no ano de 2013 o governo aprovou a Resolução número 695/13 que trata da Política Estadual de Práticas 


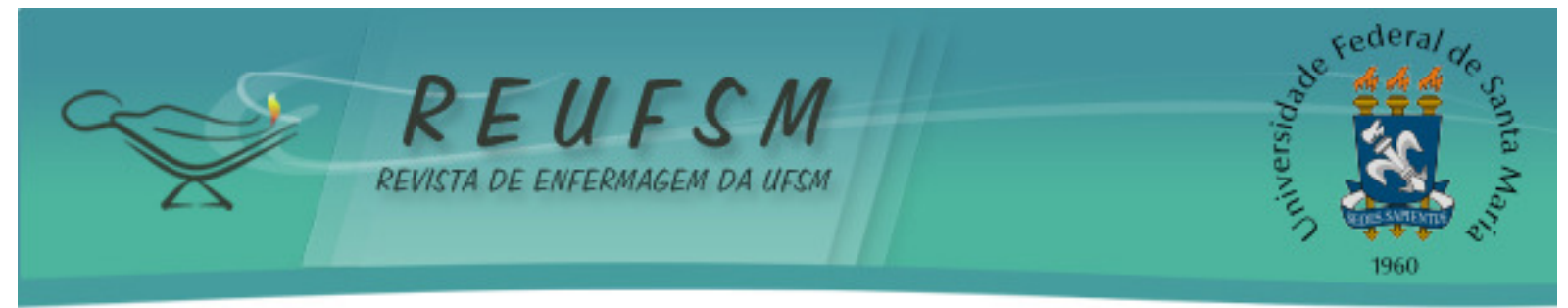

Integrativas e Complementares (PIC), com o objetivo de implementar as práticas integrativas no Sistema Único de Saúde (SUS/RS). ${ }^{7}$

Destaca-se que, com este artigo, buscou-se criar um elo entre o saber popular e o saber científico, aproximando a comunidade aos trabalhadores da saúde pertencentes à mesma. Conhecer os saberes, isto é, aquilo que as pessoas apontam como referência para a realização de suas práticas e como as utilizam no cotidiano é uma forma de possibilitar esta aproximação. Nesse caso, os saberes populares são aqueles aprendidos nas vivências, quer nas relações familiares, nas redes ampliadas que contemplam os vizinhos e amigos, acrescidos pelo conhecimento científico, interpretado pelo saber popular. ${ }^{8}$

Nessa pesquisa, foram consideradas apenas plantas colhidas frescas ou secas in natura, as quais são empregadas para o consumo de chá caseiro. Dessa forma, foram desconsiderados todos os outros tipos de plantas e chás industrializados.

Nesta perspectiva, questiona-se: Quais os saberes e práticas de moradores da região urbana acerca do uso de plantas medicinais como forma terapêutica no cuidado à saúde? Assim, objetivou-se conhecer os saberes e as práticas dos moradores da região urbana de um município do noroeste do estado do Rio Grande do Sul (RS), sobre a utilização de plantas medicinais como forma terapêutica no cuidado à saúde.

\section{MÉTODO}

Trata-se de pesquisa qualitativa, constituída por um estudo exploratório e descritivo. A pesquisa qualitativa trabalha com interpretações das realidades sociais e com a entrevista em profundidade. ${ }^{9}$

Este estudo foi realizado com pessoas moradoras na área urbana de uma Estratégia Saúde da Família (ESF) em um município no noroeste do estado do Rio Grande do Sul, a qual possuía 1208 famílias pertencentes a sua área de abrangência. Cabe ressaltar que esta pesquisa faz parte de um levantamento realizado anteriormente, ${ }^{10} \mathrm{com}$ o qual foi possível verificar as plantas mais utilizadas no município e ver quais destas estavam regulamentadas pela Agência Nacional de Vigilância Sanitária (ANVISA), Resolução $N^{\circ} 10$, de 9 de março de $2010 .^{11}$

A coleta de dados ocorreu nos domicílios, por meio de entrevista semiestruturada e observação participante, durante o período de julho a setembro de 2011.

A entrevista semiestruturada combina perguntas fechadas e abertas, em que o entrevistado tem a possibilidade de discorrer o tema em questão sem perder a indagação formulada. ${ }^{12}$ As perguntas utilizadas para a elaboração da pesquisa foram: Que plantas você costuma usar para tratar problemas de saúde? Para que serve a referida planta? Quem indicou a planta para o uso?

A observação participante costuma ser utilizada frequentemente, como estratégia complementar ao uso das entrevistas nas relações sociais com os entrevistados e em momentos considerados importantes para efeitos da pesquisa. ${ }^{12}$

Para ordenar as observações, criou-se um roteiro com quatro itens a serem observados e registrados no diário de campo, sendo eles: a origem da planta (comprada, plantio próprio ou doação); colheita, higienização, armazenamento e conservação da planta; modo de preparo da planta para a utilização; local de plantio: cercado, acesso a animais domésticos, próximo a fossas sépticas, esgoto a céu aberto, próximo a criadouro. Neste artigo, foram utilizadas anotações e observações realizadas nas residências dos participantes da pesquisa, com relação à origem da planta e ao local do plantio da mesma, assim como conversas informais com os entrevistados. 


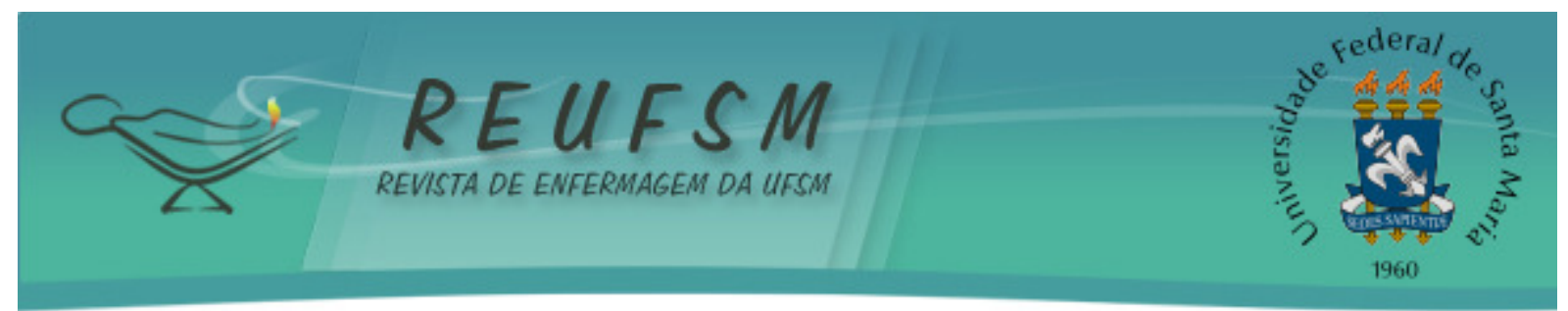

A seleção dos participantes da pesquisa foi realizada por utilização da rede de relações sociais ${ }^{13}$ ou também conhecida como método "Snow Ball", ${ }^{14}$ que consiste em um processo no qual cada informante remete o pesquisador a outros membros da sua rede de relações sociais para investigações subsequentes. As entrevistas foram realizadas até o momento em que os objetivos da pesquisa foram alcançados, o que totalizou dez pessoas.

O primeiro participante das entrevistas foi indicado pela enfermeira da ESF, os demais entrevistados foram identificados pela letra $S$, significando sujeito participante da entrevista, seguido do número da ordem da entrevista .

A rede de relações sociais teve início com a enfermeira da unidade, que recomendou o primeiro participante, sendo aconselhada uma moradora da região e conhecedora de vários chás. Ao término da entrevista essa moradora foi chamada de $\mathrm{S}^{1} \mathrm{e}$ indicou o $\mathrm{S}^{2}$, segundo participante da entrevista, que também utilizava chás para cuidar da saúde. Este sugeriu o $S^{3}$ que ao término de sua entrevista lembrou o $S^{4}$ que, segundo ele, também fazia uso de plantas medicinais e assim sucessivamente até o fechamento da rede de relações sociais.

No decorrer das entrevistas e observações, os participantes foram solicitados a informarem as plantas medicinais que costumavam utilizar para cuidar de sua saúde ou de algum membro de sua família, o que totalizou 57 espécies de plantas.

Para analisar e interpretar os resultados desta pesquisa utilizou-se a análise de conteúdo ${ }^{15}$, que consiste em um conjunto de técnicas de análise das comunicações visando obter, por procedimentos sistemáticos e objetivos de descrição do conteúdo das mensagens, indicadores que permitem a inferência de conhecimentos relativos às condições de produção/recepção (variáveis inferidas) destas mensagens. Os resultados foram organizados em temas de acordo com os objetivos das perguntas realizadas aos entrevistados e suas subsequentes respostas. Utilizou-se ainda, para análise, as observações que foram anotadas no diário de campo.

0 presente estudo encontra-se em concordância com as recomendações para a realização de pesquisas envolvendo seres humanos vigentes no período de coleta dos dados, as quais se encontram em conformidade com a Resolução do Conselho Nacional de Saúde 466/12. ${ }^{16}$ Foi aprovada pelo Comitê de Ética em Pesquisa da Universidade Federal de Santa Maria, sob o número 23081.004298/2011-31 e Certificado de Apresentação para Apreciação Ética (CAAE) 0045.0.243.000-10.

\section{RESULTADOS E DISCUSSÕES}

\section{Caracterização dos participantes da pesquisa}

Os participantes da pesquisa foram escolhidos por fazerem parte de uma rede de relações sociais, dessa maneira, geralmente era uma pessoa próxima de seu convívio e, por esse motivo, o informante sabia dizer se a pessoa fazia uso de plantas medicinais ou não.

Todos os integrantes da rede de relações sociais eram do sexo feminino, essa predominância pode estar associada ao fato da mulher ser a principal cuidadora no seio familiar. ${ }^{17} \mathrm{~A}$ idade das entrevistadas variou de 37 a 80 anos de idade. Entre as dez, quatro tinham menos de 60 anos e seis eram idosas. Considera-se idoso, de acordo com a Lei $\mathrm{n}^{\circ}$ 8.842 de 04 de janeiro de 1994 , pessoas acima de sessenta anos de idade. ${ }^{18}$ Quanto à profissão, três eram do lar, três eram aposentadas, duas eram cabeleireiras, uma era agente de saúde e uma era agricultora. A renda familiar, considerando o valor do salário mínimo da época da coleta de dados, predominou de um a três salários mínimos em quatro 


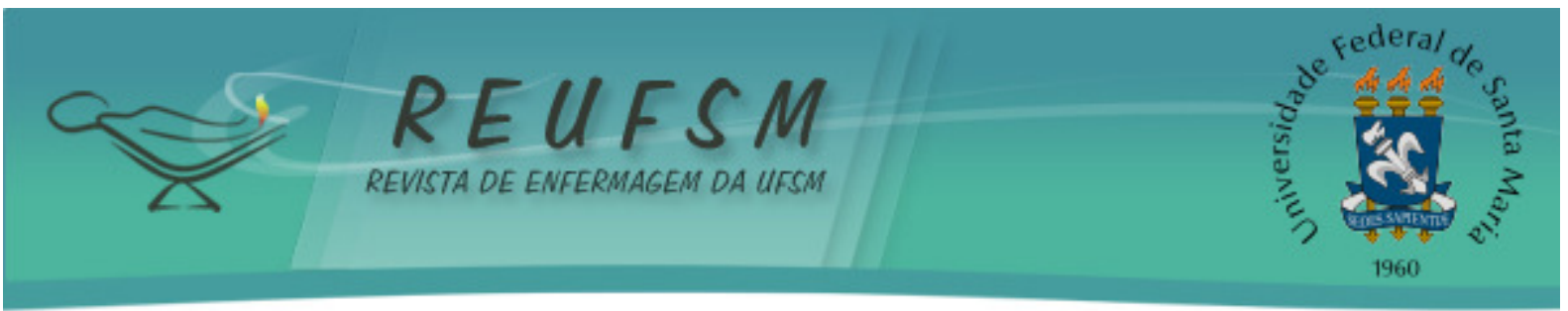

entrevistados; três pessoas declararam a renda de até um salário mínimo; duas pessoas disseram ter renda de três a cinco salários, e uma pessoa referiu ter renda superior a cinco salários mínimos.

Para relatar o conhecimento baseado nas práticas populares, elaboraram-se durante as entrevistas e as observações os seguintes temas: "tipos de plantas e suas indicações" e "quem indicou o uso da planta".

\section{Tipos de plantas e suas indicações}

Nessa categoria foram analisadas duas questões utilizadas para guiar as entrevistas: "que planta você costuma usar para tratar de problemas de saúde?" e "para que serve essa planta?", com o intuito de descobrir o conhecimento popular e após, poder compará-lo com o conhecimento científico.

Devido ao grande número de plantas, optou-se por trabalhar com as três ou mais vezes referidas pelos entrevistados. Assim, totalizaram-se dez espécies de plantas: Apium graveolens L. (Aipo); Plectranthus barbatus Andrews (Boldo); Chamomilla recutita (L.) (Camomila); Equisetum hyemale L. (Cavalinha); Foeniculum vulgare Mill. (Funcho); Mentha x piperita L. (Hortelã); Malva parviflora L. (Malva); Achyrocline satureioides (Lam.) DC. (Marcela); Cunila microcephala Benth. (Poejo) e Plantago major L. (Tansagem) (Quadro 1).

\begin{tabular}{|c|c|c|}
\hline $\begin{array}{l}\text { Nome científico/ } \\
\text { Nome popular }\end{array}$ & $\begin{array}{l}\text { Indicações populares } \\
\text { referidas }\end{array}$ & Algumas indicações científicas ${ }^{19}$ \\
\hline $\begin{array}{l}\text { Apium graveolens } \\
\text { Aipo }\end{array}$ & $\begin{array}{ll}- & \text { Febre } \\
\text { - } & \text { Gripe } \\
\text { - } & \text { Infecções em geral }\end{array}$ & $\begin{array}{ll}\text { - } & \text { Antitérmico } \\
\text { - } & \text { Expectorante } \\
\text { - } & \text { Antiasmático } \\
\text { - } & \text { Afecções febris }\end{array}$ \\
\hline $\begin{array}{l}\text { Plectranthus barbatus } \\
\text { Boldo }\end{array}$ & $\begin{array}{ll}\text { - } & \text { Estômago } \\
\text { - Náuseas } \\
\text { - Fígado }\end{array}$ & $\begin{array}{l}\text { - Afecções hepáticas } \\
\text { - Afecções gástricas }\end{array}$ \\
\hline $\begin{array}{l}\text { Matricaria chamomilla } \\
\text { Chamomilla recutita } \\
\text { Camomila }\end{array}$ & $\begin{array}{ll}\text { - } & \text { Estômago } \\
\text { - } & \text { Calmante } \\
\text { - } & \text { Terçol }\end{array}$ & $\begin{array}{l}\text { - Inflamações do } \\
\text { trato digestivo } \\
\text { - } \quad \text { tópico em inflamações de } \\
\text { pele e mucosas }\end{array}$ \\
\hline $\begin{array}{l}\text { Equisetum arvense } \\
\text { Equisetum hyemale } \\
\text { Cavalinha }\end{array}$ & $\begin{array}{ll}\text { - } & \text { Diurético } \\
\text { - } & \text { Colesterol } \\
\text { - } & \text { Quebra pedra }\end{array}$ & $\begin{array}{ll}\text { - } & \text { Diurético } \\
\text { - } & \text { Prevenção de litíase } \\
& \text { urinária } \\
\text { - } & \text { Feridas e queimaduras } \\
& \text { (uso externo) }\end{array}$ \\
\hline $\begin{array}{l}\text { Foeniculum vulgare } \\
\text { Funcho }\end{array}$ & $\begin{array}{l}\text { - Estufamento, cólica } \\
\text { - } \text { Gripe } \\
\text { - Tosse }\end{array}$ & $\begin{array}{ll} & \text { Afecções } \\
\text { gastrintestinais } \\
\text { Tratamento de } \\
\text { envenenamento }\end{array}$ \\
\hline $\begin{array}{l}\text { Mentha x piperita } \\
\text { Hortela }\end{array}$ & $\begin{array}{ll}\text { - } & \text { Tosse } \\
\text { - } & \text { Gastrite } \\
\text { - } & \text { Hipertensão } \\
\text { - } & \text { Calmante } \\
\text { - } & \text { Infecção do sangue }\end{array}$ & $\begin{array}{l}\text { - } \\
\text { - } \text { e veroblemáf digestivos } \\
\text { - Tratamento de } \\
\text { bronquites }\end{array}$ \\
\hline
\end{tabular}




\begin{tabular}{|c|c|c|}
\hline $\begin{array}{l}\text { Malva parviflora } \\
\text { Malva }\end{array}$ & $\begin{array}{l}\text { - } \\
\text { - Prtiinflamatório } \\
\text { garganta }\end{array}$ & $\begin{array}{l}\text { - } \\
\text { - } \\
\text { - }\end{array}$ \\
\hline $\begin{array}{l}\text { Achyrocline satureioides } \\
\text { Marcela }\end{array}$ & $\begin{array}{ll}\text { - } & \text { Digestão } \\
\text { - } & \text { Desarranjo } \\
\text { - } & \text { Sinusite } \\
\text { - } & \text { Febre }\end{array}$ & $\begin{array}{ll}- & \text { Digestiva } \\
\text { - } & \text { Diarreia } \\
\text { - } & \text { Antiinflamatória } \\
\text { - } & \text { Hipoglicemiante }\end{array}$ \\
\hline $\begin{array}{l}\text { Cunila microcephala } \\
\text { Poejo }\end{array}$ & $\begin{array}{l}\text { - } \quad \text { Coriza } \\
\text { - } \quad \text { Gripe } \\
\text { - Sonífero }\end{array}$ & $\begin{array}{l}\text { - } \text { Coriza } \\
\text { - } \text { Gripe } \\
\text { Problemas de peito, } \\
\text { estômago, cólica em } \\
\text { nenês }\end{array}$ \\
\hline $\begin{array}{l}\text { Plantago major } \\
\text { Tansagem }\end{array}$ & $\begin{array}{ll}\text { - } & \text { Antiinflamatório } \\
\text { - } & \text { Infecções de garganta } \\
\text { - } & \text { Circulação do sangue }\end{array}$ & $\begin{array}{l}\text { - } \text { Antiinflamatório } \\
\text { - } \quad \text { Tosse alérgica e faringite } \\
\text { - Impureza do sangue }\end{array}$ \\
\hline
\end{tabular}

Quadro 1 - Tipo de plantas, recomendação popular e científica.

Durante a análise de dados, identificou-se que, das dez plantas medicinais escolhidas para o estudo, todas possuem algumas indicações terapêuticas semelhantes com as encontradas na literatura. Porém, nem todas em sua totalidade, pois sete plantas apresentam indicações semelhantes à da literatura, mas três estão de acordo em parte. Entre as plantas medicinais que se encontram em concordância com a literatura pesquisada ${ }^{19}$ estão o aipo (Apium graveolen) citado nas entrevistas como sendo bom para febre, gripe e infecções em geral. Os estudos apontam o aipo sendo indicado como antitérmico, antiasmático, expectorante e afecções febris. ${ }^{19}$ Há também o boldo (Plectranthus barbatus), a camomila (Matricaria chamomilla), a malva (Malva parviflora), a marcela (Achyrocline satureioides), o poejo (Cunila microcephala) e a tansagem (Plantago major). Essas recomendações que vão ao encontro das indicações científicas, podem ser observadas nas falas a seguir:

[...] daí pra cólica, diarreia, coisa assim, eu faço chá de marcela, eu utilizo bastante o chazinho de marcela [...]. $\left(\mathrm{S}^{2}\right)$

[...] o aipo é muito bom para a garganta. O aipo é outro remédio pra qualquer tipo de infecção [...].( $\left(\mathrm{S}^{3}\right)$

Foi possível também observar que na casa do $S^{3}$ há várias espécies de plantas medicinais, pois ela gosta de cultivar todos os chás que costuma tomar no dia a dia.

Ao se tratar das plantas medicinais, cujas indicações populares não corresponderam na sua totalidade às indicações encontradas nas literaturas consultadas, estão a cavalinha (Equisetum hyemale), o funcho (Foeniculum vulgare) e a hortelã (Mentha $x$ piperita). A cavalinha recebeu as indicações como diurético, quebra pedra sendo adequada para o colesterol, porém, ao consultar a literatura, ${ }^{19}$ constataram-se as seguintes indicações: diurético, prevenção de litíase urinária, tratamento de feridas e queimaduras como uso externo. Dessa forma, não foi encontrado nada que demonstrasse a eficiência da cavalinha no tratamento do colesterol, como demonstrado na fala abaixo. 


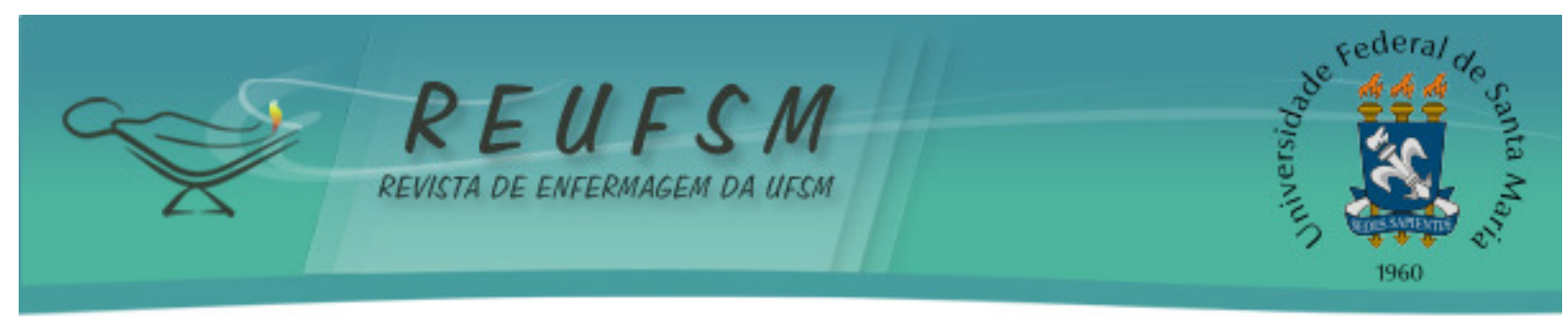

[...] ele [cavalinha] é diurético, ele elimina colesterol, ajuda o rim. $\left(\mathrm{S}^{4}\right)$

O funcho foi indicado para tratamento de estufamento, cólicas abdominais, tosse e gripe. Porém, na literatura, ${ }^{19}$ constatou-se o uso deste para afecções gastrintestinais e tratamento de envenenamento. Não foi encontrado em trabalhos científicos o funcho como planta eficaz no tratamento da gripe e tosse,${ }^{19}$ conforme visto na fala abaixo.

\section{[...] o funcho também é pra tosse, pra gripe no caso [...].( $\left(\mathrm{S}^{2}\right)$}

A terceira planta, que não foi ao encontro da literatura com as mesmas indicações que os entrevistados citaram, foi a hortelã. Esta teria por finalidade o tratamento de tosse, gastrite, hipertensão, calmante e infecção do sangue, mas na literatura ${ }^{19}$ constatouse que ela é indicada no tratamento de problemas digestivos e como vermífugos, ou no tratamento de bronquites, entre outras propriedades, que também não vão ao encontro das populares, como pode ser visto na fala da $\mathrm{S}^{3}$.

[...] a hortelã se você tiver nervoso, aquela sensação de parece que alguma coisa está te apertando, aquela angústia, você faz um chazinho e toma bem friozinho e coloca um pouquinho de açúcar e logo está tranquilo, e é chá que não vai baixar muito a pressão. $\left(\mathrm{S}^{3}\right)$

No que se refere às três plantas que não foram ao encontro total com a literatura específica, ${ }^{19}$ não se deve afirmar que estas não possuem poder curativo para tais indicações citadas pelos entrevistados, mas sim que pode ainda haver lacunas no conhecimento sobre os poderes terapêuticos de tais plantas sendo, dessa forma, um incentivo a novos estudos sobre as mesmas.

Com relação à finalidade da utilização dos chás pela população, foi possível perceber que cinco dos dez entrevistados, utilizam os chás com o objetivo de tratar de problemas estomacais; em segundo lugar, com quatro indicações, são feitos os chás para tratar de gripe e tosse; em terceiro lugar com duas indicações cada um, estão os chás para tratar febre e que são utilizados como calmante e antiinflamatório. Destaca-se, também, plantas utilizadas para tratar náuseas (um), problemas no fígado (um), infecções em geral (um), infecções no sangue (um), na garganta (um), terçol (um), desarranjo (um), sinusite (um), coriza (um), problemas de garganta e útero (um) assim, como problemas na circulação do sangue (um). Também teve indicações de plantas que funcionam como diuréticos (um), hipotensores (um), soníferos (um) e para auxílio na eliminação de cálculos renais (um).

Sendo assim, é visível o valor que os chás possuem no cuidado à saúde dos entrevistados, ressaltando-se a importância do profissional da saúde ter sustentação científica sobre o tema, para poder contribuir com a comunidade em que atua e evitar o uso incorreto e indevido das plantas medicinais.

\section{Quem indicou o uso da planta}

Neste tema será abordado quem realizou a recomendação do uso das plantas medicinais para os entrevistados, com o intuito de conhecer de que forma o saber popular está sendo transmitido para as pessoas pertencentes à referida ESF Urbana.

No decorrer das entrevistas, percebeu-se que o uso da maioria das plantas citadas ocorre no seio familiar. Os dez entrevistados relataram ter plantas indicadas pela sua 


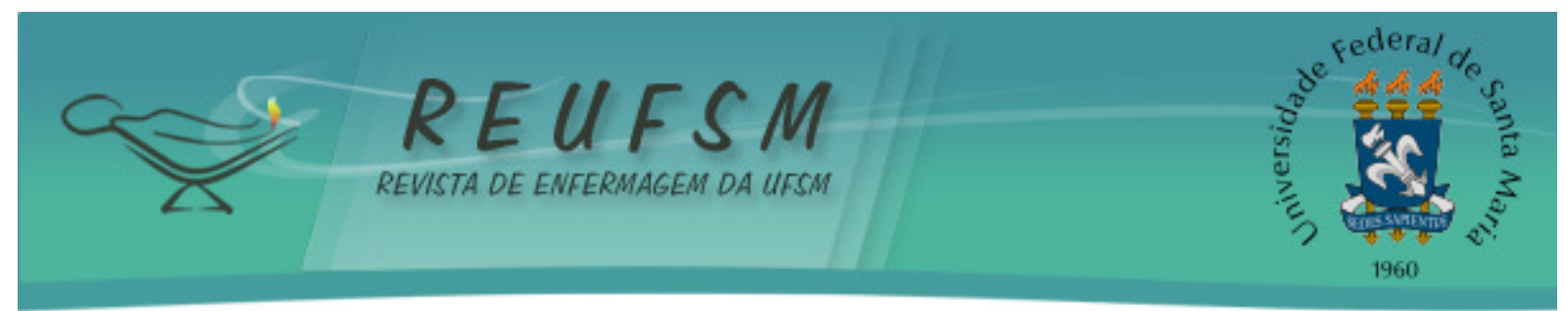

família, avós, pais, tios e irmãos. Em um total de trinta e nove vezes que as dez plantas estudadas no momento foram citadas, apenas sete vezes tiveram outra origem que não familiar, sendo ela através de vizinhos, amigos, sogra ou pastoral da saúde. Essas constatações podem ser observadas nas seguintes falas:

[...] é do tempo da minha mãe, tudo esses chazinhos, é que a gente morava no interior e nós usávamos muito remédio caseiro [...]. $\left(\mathrm{S}^{9}\right)$

[...] ah, essa aí (marcela) é do tempo do "epa", a minha avó e avô, lá por lá $[\ldots] \cdot\left(\mathrm{S}^{8}\right)$

Observou-se que na casa do $\mathrm{S}^{2}$, há uma idosa morando junto da família e foi possível perceber que esta idosa incentiva o uso dos chás para o restante da família, que acaba adquirindo os mesmos hábitos.

Estes achados vão ao encontro de estudos realizados em outras comunidades, o que reforça o modo de transmissão familiar deste conhecimento milenar que é a utilização de plantas medicinais para o cuidado em saúde, destacando-se a figura da mulher (mãe e avó) na prestação do cuidado e transmissão do conhecimento. ${ }^{20-21}$

Assim, salienta-se a importância do enfermeiro estar envolvido com a comunidade, a fim de conhecer os costumes familiares e poder auxiliar as famílias, compartilhando conhecimentos sobre as práticas realizadas pelos moradores da comunidade, melhorando, dessa forma, o atendimento prestado no cuidado à saúde da população.

\section{CONCLUSÃO}

Nesta pesquisa foi dada ênfase ao uso das plantas medicinais como forma terapêutica no cuidado à saúde de pessoas da área urbana de um município da região Norte do Rio Grande do Sul. Os pesquisados relataram seus conhecimentos, experiências e vivências com essa terapia complementar.

Salienta-se que, durante a pesquisa, pode-se observar um conhecimento dos entrevistados sobre as espécies de plantas e como este conhecimento é importante para suas vidas pois falam, com muito orgulho, sobre os chás de que fazem uso. Outro fator é o papel da família no cuidado em saúde e preservação da biodiversidade. Os entrevistados relatam ter herdado essa prática de seus pais ou avós. Da mesma forma como usavam quando eram crianças, continuam a usar até hoje, inclusive com seus filhos.

0 estudo destaca a importância das plantas medicinais como forma terapêutica no cuidado à saúde do sujeito, diante do qual o enfermeiro possui papel importante, especialmente nas comunidades com Estratégia Saúde da Família. Cabe ao Enfermeiro uma escuta acolhedora, que perceba a realidade de cuidado integral deste sujeito, bem como procurando atualizar-se acerca da correta utilização das plantas medicinais.

0 cuidado de enfermagem, bem como dos demais profissionais de saúde, poderá ser beneficiado ao conhecer ou reconhecer a utilização das plantas por pessoas assistidas. Por isso sugere-se a realização de outras pesquisas nesta temática, uma vez que, tem se como limitação desse estudo a realização em um único cenário.

\section{REFERÊNCIAS}

1. Brasil. Ministério da Saúde. A fitoterapia no SUS e o programa de Pesquisas de Plantas Medicinais da Central de Medicamentos. Brasília (DF): MS; 2006. 


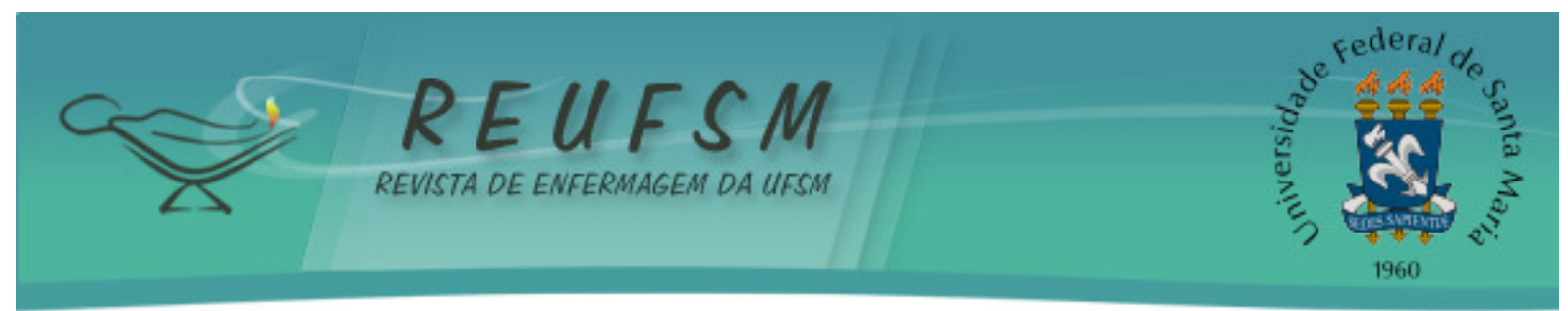

2.Tomazzoni MI, Negrelle RRB, Centa ML. Fitoterapia popular: a busca institucinal enquanto prática terapêutica. Texto \& Contexto Enferm. 2006;15(1):115-21.

3. Silva FLA, Oliveira RAG, Araújo EC. Use of medicinal plants by the elders at a family health estrategy . Rev Enferm UFPE on line. 2008 jan./mar.;2(1):9-16.

4. Badke MR, Budó MLD, Alvim NAT, Zanetti GD, Heisler EV. Saberes e práticas populares de cuidado em saúde com o uso de plantas medicinais. Texto \& Contexto Enferm [Internet]. 2012 [acesso em 2014 nov 10];21(2):363-70. Disponível em: http: / / www.scielo.br/scielo.php?script=sci_arttext\&pid=S0104-

07072012000200014\&lng=pt\&nrm=isso doi http://dx.doi.org/10.1590/s010407072012000200014.

5. Soares AS. As plantas medicinais como alternativa terapêutica. Petrópolis, RJ: Vozes; 2007.

6. Brasil. Ministério da Saúde. Programa Nacional de Plantas medicinais e Fitoterápicos. Brasília (DF): MS; 2009.

7. Rio Grande do Sul (Estado). Secretaria da Saúde. Resolução № 695, de 20 de dezembro de 2013. Aprovar a Política Estadual de Práticas integrativas e Complementares [Internet]. Diário Oficial do Estado do Rio Grande do Sul, Porto Alegre, RS; 2012 maio 23 [acesso em 2014 jan 10]. Disponível em: http://www.saude.rs.gov.br/upload/1388163773_cibr695_13.pdf.

8. Silva FM, Budó MLD, Garcia RP, Sehnem GD, Schimith MD. Práticas de vida de portadores de hipertensão arterial. Rev Enferm UERJ. 2013 jan/mar;21(1):54-9.

9. Bauer MW, Gaskell G. Pesquisa qualitativa com texto, imagem e som: um manual prático. 8a Ed. Petrópolis, RJ: Vozes; 2010.

10. Battisti C, Garlet TMB, Essi I, Horbach RK, Andrade A, Badke MR. Plantas medicinais utilizadas no município de Palmeira das Missões, RS, Brasil. Rev Bras Bioci. 2013;11(3):338-48.

11. Ministério da Saúde. Agência Nacional de Vigilância Sanitária (ANVISA). Resolução da Diretoria Colegiada (RDC) $n^{\circ} 10$, de 9 de março de 2010. Dispõe sobre a notificação de drogas vegetais junto à Agência Nacional de Vigilância Sanitária (ANVISA) e dá outras providências. Diário Oficial [da] República Federativa do Brasil, Poder Executivo, Brasília, DF; 2010 mar 10. Seção 1, p. 52-9.

12. Minayo MCS. O desafio do conhecimento: pesquisa qualitativa em saúde. $20^{\mathrm{a}}$ ed. São Paulo: Hucitec; 2010.

13. Víctora CG, Knauth DR, Hassen MNA. Pesquisa qualitativa em saúde: uma introdução ao tema. Porto Alegre: Tomo Editorial; 2000. p. 37.

14. Albertasse PD, Thomaz LD, Andrade MA. Plantas medicinais e seus usos na comunidade da Barra do Jucu, Vila Velha, ES. Rev Bras Plantas Med. 2010;(12)3:250-60.

15. Bardin L. Análise de conteúdo. Tradução de Luís Antero Reto e Augusto Pinheiro. Lisboa/Portugal: Presses Universitaires de France; 2011.

16. Brasil. Ministério da Saúde. Conselho Nacional de Saúde. Resolução CNS $n^{\circ} 466$, de 12 de dezembro de 2012. Aprova diretrizes e normas regulamentadoras de pesquisas envolvendo seres humanos. Diário Oficial da República Federativa do Brasil. Brasília (DF); 2012.

17. Badke MR, Budó MLD, Silva FM, Ressel LB. Plantas medicinais: o saber sustentado na prática do cotidiano popular. Esc Anna Nery Rev Enferm. 2011;(15)1:132-9. 


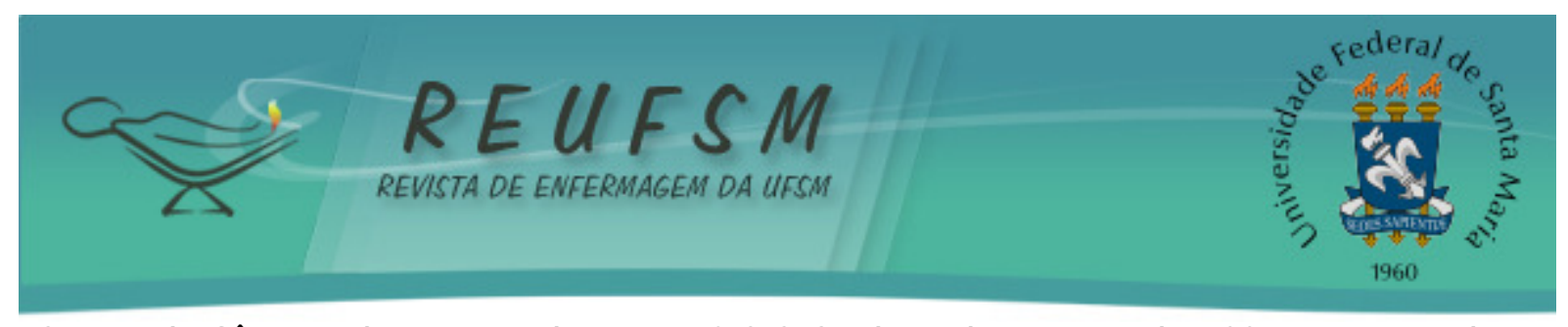

18. Brasil. Câmara dos Deputados. Lei $n^{\circ} 8.842$, de 4 de janeiro de 1994. Dispõe sobre a política nacional do idoso, cria o Conselho Nacional do Idoso e dá outras providências. Brasília (DF); 1994.

19. Lorenzi H, Matos FJA. Plantas medicinais no Brasil: nativas e exóticas cultivadas. 2.ed. Nova Odessa, SP: Instituto Plantarum; 2008.

20. Budó MLD, Resta DG, Denardin JM, Ressel LB, Borges ZN. Práticas de cuidado com relação à dor - a cultura e as alternativas populares. Esc Anna Nery Rev Enferm. 2008; 12(1):90-6.

21. Heisler EV, Badke MR, Andrade A, Rodrigues MGS. Saber popular sobre a utilização da planta Anredera cordifolia (fat leaf). Texto \& Contexto Enferm. 2012;21(4):937-44.

Data de recebimento: 08/05/2015

Data de aceite: 18/04/2016

Contato do autor responsável: Marcio Rossato Badke.

Endereço postal: Universidade Federal de Santa Maria. Centro de Ciências da Saúde. Departamento de Enfermagem. Av Roraima, $\mathrm{n}^{\circ} 1000$. Cidade Universitária. Bairro Camobi. CEP: 97105-900. Santa Maria, RS, Brasil

E-mail: marciobadke@gmail.com 